\title{
ORALLY DISINTEGRATING PREPARATIONS: RECENT ADVANCEMENT IN FORMULATION AND TECHNOLOGY
}

\author{
* Reeta Rani Thak ur, Sonia Narwal \\ M.M. College of Pharmacy, M.M. University Mullana, Ambala-133207 \\ Corresponding author's: E-mail-reetabit@gmail.com, PH.NO-805993015
}

Received 03 March 2012; Revised 03 April 2012; Accepted 21 April 2012, Available online 15 May 2012

\begin{abstract}
:
Oral route is the most convenient route for drug administration due to the highest component of compliance mainly the pediatrics and geriatrics. It is regarded as the most economical and safest method of drug delivery. Formulation of a orally disintegrating dosage form is beneficial for patients suffering from motion sickness, repeated emesis, mental disorder and dysphasia because they cannot swallow large quantity of water and it is easy to administer. The unique property of orally disintegrating dosage form is that they are readily disintegrating and dissolves in saliva and avoids the requirement of water which is the major benefit over conventional dosage form. Further, drug having the satisfactory absorption from the oral mucosa can be formulated in such type of dosage form.. This article includes requirement for orally disintegrating tablets, orally disintegrating films, chewing gums, oral wafers and buccal patches ,their advantages,disadvantages, challenges in formulation,patented technologies, various technologies developed for formulated orally disintegrating dosage form ,super disintegrating agents in the formulation, evaluation method and various marketed products.

Keywords: Orally disintegrating tablets, Superdisintegrants, Oral route, Chewing gums, orally disintegrating films, Buccal patches
\end{abstract}

\section{INTRODUCTION:}

A vast variety of pharmaceutical research is directed at developing new dosage form. Orally disintegrating dosage form is the widely preferred commercial product among the various dosage forms. The oral cavity is the most favorable site for administration of orally disintegrating dosage form due to the ease of ingestion. Oral route is used for the administration of various dosage forms such as orally disintegrating tablets, films, patches, wafers, chewing gums etc. In the recent trend orally disintegrating tablets gaining popularity because it is easy to administer and doesn't requires additional water. Che wable tablets are palatable and can be chewed before swallowing. The orally disintegrating films can be administered in the oral cavity and disintegrates within a second to give better theuraptic action. Chewing gums are used for local and systemic treatment. Suitable drug candidates for such system include cardiovascular agents, neuroleptics, analgesic, antiallergics and drug for erectile dysfunction. Such a dosage form disintegrates quickly when placed on tongue; release the drug that dissolves in saliva. This results in greater bioavailability and rapid onset of action than conventional dosage form ${ }^{1}$.

\section{ORALLY DIS INTEGRATING TAB LETS :}

The centre for drug evaluation and Research defines orally disintegrating tablets as a dosage form -“A solid dosage form which disintegrates rapidly within a matter of seconds when placed under the tongue". The disintegrating time for orally disintegrating tablet varies from seconds to minutes, depends upon the size of tablet and formulation. European pharmacopeia defined orally disintegrating tablets as-"Uncovered tablet which disperse before ingestion in the buccal cavity". Different technological techniques such as freeze drying or moulding or direct compression etc.are used to prepare the formulation of this type in the pharmaceutical market ${ }^{2}$

\section{DES IRED CHARACTERIS TICS OF ODT:}

1] Bioavailability

2] Rapid drug therapy intervention is possible ${ }^{4}$.

3] Sufficient mechanical strength

4] Allow high drug loading 9.

5] Rapid onset of theuraptic action

6] Good compatibility with development technology 7 .

7] Leaves no residue in mouth after oral ad ministration

8] Stability

9] Conventional packaging and processing equipments allows the manufacturing of tablets at low cost 4,9 .

10] Be compatible with taste masking and other excipients

\section{ADVANTAGES OF ODT:}

1] It can be administered to the patient who cannot swallow conventional dosage form such as bedridden patients, elderly and patient effected by renal failure and thus improves patient compliance ${ }^{6}$

2] It is suitable for bedridden, disabled, traveler and busy persons who does not contain water every time 5 .

3] Good mouth feel property helps to mask the bitterness of medicines.

4] Rapid drug therapy intervention.

5] It provides rapid absorption of drugs and increased bioavailability. 

conventional formulation due to physical obstructions is avoided and provides safety.

TABLE 1: SOME OF THE DRUG CANDIDATES FOR ORALLY DISINTEGRATING TABLETS ${ }^{3,10}$.

\begin{tabular}{|c|c|}
\hline CATEGORY & EXAMPLES \\
\hline Anti Diabetics & Glipizide,Tolbutamide, Glibencla mide,To laza mide, Gliclazide, Chlorpropamide etc. \\
\hline Anti Hypertensive & Mino xid il,Nimodip ine,A mlod ipine,Terazosine HCl, Prazos in HCl,Diltiaze m etc \\
\hline Anti Histamines & Loratadine,Cetrizine,Cinnarizine,Tripro lid ine,Fe xo fenadine etc \\
\hline Anti Arrhythmics & Quinid ine sulphate,Amiodarone $\mathrm{HCl}$,Dis opyramide \\
\hline Diuretics & Acetazola mide,Spironolactone,Furosemide,A miloride,Ethacrynic acid etc \\
\hline Anti Arrhythmics & Quinid ine sulphate,Amiodarone $\mathrm{HCl}$,Disopyramide \\
\hline Analgesics & $\begin{array}{l}\text { Ibuprofen, Ketoprofen, Dic lofenac sodium, Mefenamic acid, Piroxicam, Oxyphenbutazone, } \\
\text { Indomethacin etc. }\end{array}$ \\
\hline \multirow[t]{2}{*}{ Antibacterial agents } & Penincillin, Rifampicin, Nalidixicacid, Trimethoprim, Suphacetamide, \\
\hline & Ciproflo xacin, Tetracyclin,Do xycyclin etc. \\
\hline Anti Depressants & Notriptyiline $\mathrm{HCl}$, Trazodone $\mathrm{HCl}, \mathrm{A}$ mo xap ine,Minaserin $\mathrm{HCl}$ etc \\
\hline Corticosteroi ds & Hydrocortis one,Betamethas one,Beclo methas one,Prednisolone etc. \\
\hline $\begin{array}{l}\text { Anti Protozoal } \\
\text { agents }\end{array}$ & Metronidazole,Tinidazole,Ben znidazole,Omida zole \\
\hline Anti Helmintics & Mebendazole,Albendazole,Livermectin,Dichlorophen, Thiabendazole,Praziquantal etc. \\
\hline $\begin{array}{l}\text { Gastro-intestinal } \\
\text { agents }\end{array}$ & Ranit idine $\mathrm{HCl}$, Famotidine, Cimitidine, Omeprazole, Ondansteron $\mathrm{HCl}$, Do mperidone etc. \\
\hline
\end{tabular}

\section{DISADVANTAGES OF ODT's:}

1] It requires proper packaging for safety and stabilization of stable drugs.

2] It is hygroscopic in nature, so must kept in dry place ${ }^{4,8}$.

3] It shows the fragile, effervescence granules property ${ }^{1 .}$

4] If not formulated properly, it may leave unpleasant taste in mouth.

5] Since the tablet having insufficient mechanical strength, so careful handling is required ${ }^{3}$.

\section{TRADITIONAL TAS TE MAS KING TECHNOLOGIES IN ODTs ${ }^{17}$ :}

1] Taste masking by Ion-exchange Resins.

2] Taste masking by coating with Hydrophilic Vehicles.

3] Taste masking using Flavors and Sweeteners.

4] Taste masking using Lipophillic Vehicles

Table 2: Technologies Used For Masking the Taste of Active Ingredient ${ }^{17,18,20}$.

\begin{tabular}{lllll}
\hline S.No & Technology & Excipients & $\begin{array}{l}\text { Active } \\
\text { Ingredient }\end{array}$ & Method \\
\hline $\mathbf{1}$ & Fluidized bed coating & $\begin{array}{l}\text { Methyl cellulose, HPMC, } \\
\text { Acesulfame }\end{array}$ & $\begin{array}{l}\text { Tamoxifen, caffeine, } \\
\text { acetaminophen }\end{array}$ & $\begin{array}{l}\text { Coating completed in3 } \\
\text { minutes. Internal temperature } \\
\text { maintained at 115 degree F. } \\
\text { MC and AS solution charged } \\
\text { to fluidized bed drier. }\end{array}$ \\
$\mathbf{2}$ & Pelletization process & $\begin{array}{l}\text { Dryblend-Aspartame, HPC and } \\
\text { Gum arabic }\end{array}$ & Loratidine & $\begin{array}{l}\text { Crushed ice was mixed with dry } \\
\text { blend mixture to form Spherical } \\
\text { particles. }\end{array}$ \\
$\mathbf{3}$ & Infusion method & Sucralose, Fluoxetine and PVP & Fluoxetine & $\begin{array}{l}\text { Propylene glycol: water was used } \\
\text { mix dry blend HPMC was } \\
\text { added. }\end{array}$ \\
& Agglomeration process & Sweetner, HPMC, Silicon-di-oxide & Polythiazide & $\begin{array}{l}\text { Sweetener solution sprayed on dry } \\
\text { blend to form agglomerate } \\
\text { Granules. }\end{array}$ \\
\hline
\end{tabular}




\section{FORMULATION ASPECTS IN DEVELOPING ODT:}

ODT's are formulated by several processes, which differ in their methodologies and vary in various properties such as:

1] Taste and mouth feel ${ }^{2}$.

2] Mechanical strength of tablets ${ }^{6}$.

3] Drug dissolution in saliva.

4] Bioavaibility.

5] Stability.

6] Swalloability

\section{CHALLENGES IN FORMULATING ORALLY DISINTEGRATING TABLETS :}

\section{1] Mechanical strength:}

In order to swallow ODTs to disintegrate in the oral cavity, they are either made of porous or soft molded matrices, which makes tablet friable and difficult to handle and hence requires peel-off blister packing which increases its $\operatorname{cost}^{11,12 \text {. }}$

\section{2] Pal atability:}

Since most drugs are unpalatable, orally disintegrating drug delivery system contains medicament in taste masked form ${ }^{13}$ It dissolves in patient oral cavity, thus release the active ingredient which comes in contact with the taste buds ${ }^{5}$.

\section{3] Aque ous solubility:}

Water soluble drugs pose various formulation challenges results in freezing point depression and formation of glassy solids that may collapse upon drying. Such collapse can be prevented by using various matrix forming excipients like mannitol ${ }^{11,15}$

\section{4] Amount of drug:}

The application for technologies used for ODTs is limited by the amount of drug into each unit dose $\mathrm{e}^{14}$.The drug dose must be lower than $400 \mathrm{mg}$ for insoluble drugs and $60 \mathrm{mg}$ for soluble drugs ${ }^{12}$

\section{5] Size of tablet:}

The easiest size of tablet to swallow is $7-8 \mathrm{~mm}$ while the easiest size to handle is $8 \mathrm{~mm}$. Therefore, tablet size that is easy to handle and easy to take is difficult to achieve.

\section{6] Hygr os copicity:}

Many orally disintegrating dosage forms are hygroscopic in nature ${ }^{12.5}$. Hence they need protection from hu mid ity.

\section{MECHANIS M OF ODTs ${ }^{16}$ :}

It involves the following mechanis $\mathrm{m}-$

1] Incorporation of an appropriate disintegrating agent in the tablet formulation.

2] For rapid disintegration and dissolution of the tablet, water must quickly enter into tablet matrix.

3] Tablet is broken down into smaller particles.
EXCIPIENTS US ED FOR PREPARATION OF ODTS $5,16,17,9$.

1] Superdisintegrants-It increases the rate of disintegration and dissolution. For the success of orally disintegrating tablet, the tablet having quick dissolving property which is achieved by super disintegrants.Examples are- Crospovidone, MCC, Sodium starch glycolate, CMC, Carboxy methyl cellulose and modified corn starch.

2] Sweeteners and sugar based excipients-Sugar based excipient act as bulking agents. They exhibit high aqueous solubility and sweetness and impart taste masking property. Examples are-Aspartame, Sugar derivative, Dextrose, Fructose, Mannitol, Sorbitol, Maltose etc.

3] Flavors-It increases patient compliance and acceptability. Examples are-Vanilla, Citrus oil, Fruit essence, Eucalyptus oil, Clove oil, Peppermint oil etc.

4] Surface Active agents-It reduces interfacial tension and thus enhances solubilization of ODTs.Examples areSodiu mlaurlysulfate,

Polyoxyethylene sorbitan fatty acid esters, Polyo xyethylene steartes etc.

5] Binder-It maintains integrity of dosage form. Examples are-PVP, Polyvinylalchol, Hydroxy propyl methylcellu lose.

6] Colour-It enhances appearance and organoleptic properties of dosage form. Examples are-Sunset yellow, Red iron oxide, A maranth ${ }^{3}$.

7] Lubricants-It helps reduces friction and wear by introducing a lubricating film. Examples are-Stearic acid, Magnesium stearte, Zinc stearte, Talc, Polyethylene glycol, Liquid paraffin, Colloidal silicon-di-oxide etc.

8] Fillers-It enhances bulk of dosage form. Examples areMannitol, Sorbitol, Xylitol, Calcium carbonate, Magnesium carbonate, Calcium sulfate, Magnesium trisilicate etc.

\section{TECHNIQUES USED FOR PREPARATION OF ODT's:}

A] Conventional techniques: Various conventional techniques are available for preparation of ODT's are-

1] Freeze drying: It is a process in which water is sublimated from the product after freezing. In this heat sensitive drugs and biological are dried at low temperature that allows removal of water by sublimation ${ }^{25}$.

2] Sublimation: In these, inert solid ingredient that volatilized readily was added to other tablet ingredient and mixture is compressed into tablets. The volatile material was then removed by the process of sublimation ${ }^{19,37}$.

3] Spray-drying: It produces very fine and highly porous powder. Tablets prepared from spray drying disintegrate within $20 \mathrm{sec}$ when immersed in an aqueous mediu $\mathrm{m}^{27}$.

4] Molding: In these, water soluble ingredients are used to prepare molded tablets so that tablet dissolves rapidly. Molded tablets are very less compact then compressed tablets and exhibit porous structure for rapid dis solution.

5] Mass-extrusion: It involves softening the active blends using the solvent mixture of water soluble PEG. The ISSN: 2250-1177
CODEN: JDDTAO 
granules of bitter tasting drugs are coat by dried cylinders and hence masking their bitter taste ${ }^{26,28}$.

6] Disintegrates addition: Because of its easy implementation and cost effectiveness, it is a popular technique for formulating ODT's.The basic principle involved is addition of superdisintegrants in optimum conc.

7] Direct compression: It is the easiest way of manufacturing tablets. It consists of a limiting number of processing steps, conventional equipments and commonly available excipients. Also it requires few unit operations as compared to wet granulation ${ }^{7,20}$.

B] Patented technologies: Various patented technologies available for preparation of ODT's are-

1] Flashtab Technology: In these, tablets consists active ingredient in the form of micro crystals. It is conventional tableting technology.Prographarm laboratories have patented the flashtab technology $\mathrm{y}^{29}$.

2] Wow tab Technology: It involves adequate dissolution rate and hardness .It is patented by "Yamanouchi Pharmaceuticals Co". Wow means without water.

3] Flash dose Technol ogy: It requires greater surface area for dissolution. Flash dose tablets consist of self binding shear form matrix termed as "floss". It has been patented by "Fuisz".
4] Durasolv Technology: It is a patented technology of "CIMA" labs. It consists of druf, fillers and lubricant. It requires low amount of active ingredient ${ }^{23}$.

5] Zydis Technology: It involves quick dissolution, increased bioavailability and self-preserving. It involves softening the active blends using the mixture of methanol and polyethylene glycol.

6] Orasolv Technology: It is patented technology of "CIMA" labs. It involves quick dissolution and taste masking of active ingredient ${ }^{29,37}$.

EVALUATION OF ODT's ${ }^{9,11,18}$ :

Various evaluating parameters of ODT's are-

1] Weight variation.

2] Hardness.

3] Friability Test.

4] Disintegration Test.

5] Mechanical strength.

6] Uniformity of dispersion.

7] Wetting time.

8] In-Vitro disintegration time.

9] In-Vitro dis solution time.

10] Stability studies.

Table 3: Some of the Marketed Products of ODT's ${ }^{17,22,30,35}$ :

\begin{tabular}{|c|c|c|c|}
\hline S.NO. & BRAND NAME & DRUG/ PHARMACEUTRICAL & COMPANY \\
\hline 1 & Benadryl fast melt & Diphenhydramine & Pfizer \\
\hline 2 & Rofaday MT & Rofico xib & Lupin \\
\hline 3 & Do mray MD & Do mperidone & Ray Remedies \\
\hline 4 & Benadryl fast melt & Diphenhydramine & Warner La mbert \\
\hline 5 & Torro x MT & Rofico xib & Torrent \\
\hline 6 & Feldene melt & Piroxicam & Pfizer \\
\hline 7 & Febrectol & Paracetamol & Prographarm \\
\hline 8 & Kemstro & Baclofen & Schwarz Pharma \\
\hline 9 & Mosid MT & Mos apride & Torrent \\
\hline 10 & Maxalt-MLT & Rizatriptan Ben zoate & Merck \\
\hline 11 & Nimulid MD & Nimusulide & Panacea \\
\hline 12 & Nulev & Hyoscyamine sulfate & Schwarz Pharma \\
\hline 13 & Pepcid ODT & Famotidine & Merck \\
\hline 14 & Klonopin Wafers & Clona xepam & Roche \\
\hline 15 & Cibalginadue FAST & Ibuprofen & Novartis Consumer Health \\
\hline 16 & Olane $\mathrm{x}$ instab & Olan zepine & Ranbaxy \\
\hline 17 & Zofran ODT & Ondansetron & GSK \\
\hline 18 & Zyprexa & Olan zepine & Eli lily \\
\hline 19 & Romilast & Montelukast & Ranbaxy lab \\
\hline 20 & Olanex instab & Olan zapine & Ranbaxy lab \\
\hline
\end{tabular}

\section{B UCCAL PATCHES:}

Buccal route of drug delivery provides direct access to the systemic circulation through the jugular vein by passing the first pass hepatic metabolism and hence increases its bioavailability ${ }^{24}$.The buccal patches can solve the problem of short residence time of oral gel on mucosa. However buccal patches can offer greater advantages and comfort then other devices such as low enzy matic activity, greater accessibility, easy withdrawal, painless administration, and 
facility to induce permeation enhancer or ph modifier in the formulation, versatility in designing as unidirectional or multidirectional release system for local or systematic action $^{19}$.

\section{ADVANTAGES OF B UCCAL PATCHES :}

1] It is well known for their good accessibility to the membrane that lines the oral cavity, which makes application co mfort ${ }^{24}$.

2] The drug gains direct entry into the systemic circulation in buccal administration, thereby passing the first pass effect. In these, rate of drug absorption is not affected by gastric emptying rate ${ }^{22}$.

3] In these, drugs are absorbed from the oral cavity and transported through the deep facial vein, internal jugular vein, braciocephalic vein into the systemic circulation.

4] The buccal drug delivery system easily administered into the buccal cavity and hence exhibit better patient compliance ${ }^{19}$.

\section{COMPOS ITION OF B UCCAL PATCHES ${ }^{21,30}$ :}

1] Active ingredient: It contains API.

2] Diluents: Lactose DC is selected as a diluents its flavoring characteristics, high aqueous solubility and its physic-mechanical properties. Other examples are starch and microcrystalline starch.

3] Pol ymers: Hy ro xyethyl cellulose,

Hydro xypropylcellulose, Polyvinylpyrrolidone, Polyvinylalchol, Carbopol etc.

4] Backing layer: Ethyl cellulose etc.

5] Sweetening agents: Aspartame, mannitol, sucralose etc.

6] Flavoring agents: Menthol, vanillin, clove oil etc.

7] Plasticizers: PEG-400, 100, Propylene glycol etc.

8] Penetration enhancer: Cyanoacrylates etc.

\section{FACTORS AFFECTING B UCCAL ABSORPTION:}

There are two factors which affect buccal absorption-

1] Membrane factors: It involves surface area for absorption, mucus layer of salivary pellicle, intercellular lipids of epithelium and degree of keratinization ${ }^{36}$.

2] Environmental factors: These include saliva and salivary glands. The thin film of saliva coats throughout the buccal mucosa and called the salivary films. The thickness of salivary film is 0.07 to $0.10 \mathrm{~mm}$. The minor salivary glands are located in the epithelial region of buccal mucosa and constantly secrets mucus on surface of buccal mucosa ${ }^{24}$.

\section{METHOD OF PREPARATION OF BUCCAL PATCHES ${ }^{35}$ :}

There are two methods available for preparation of buccal patches -

\section{1] Direct milling:}

In this method, drugs and excipients are mixed by direct milling without the need of water. Then the resultant material is rolled on a release liner. The backing material is then laminated. In these method patches are made without solvent.

\section{2] Sol vent casting:}

In these, all patch excipient and drug are co-dispersed in an organic solvent and then coated on to a sheet of release liner. After solvent evaporation a backing material is laminated onto the sheets of coated release liner until the desired thickness is achieved.

\section{EVALUATION OF B UCCAL PATCHES ${ }^{22,30,35}$ :}

\section{1] Thickness measurements:}

The thickness of each film is measured by using electronic digital micrometer at five different locations.

\section{2] Ther mal anal ysis study:}

It is done by using Differential scanning calorimetry.

\section{3] Surface PH:}

It is measured by means of a ph paper placed on the surface of a swollen patch. Buccal patches are swell when placed on the surface of agar plate.

\section{4] Mor phol ogical characterization:}

It is done by using scanning electron microscope.

5] Swelling study:

As we know buccal patches are swell when placed on the surface of agar plate. After 1 hour plates are removed from the gel plates and excess water is removed using filter paper.

\section{6] Water absor ption capacity test:}

Circular patches are prepared in simulated saliva are allowed to swell on agar plate and kept in an incubator. At various time interval samples are weighed and left to dry in a dessicator over anhydrous calcium chloride at room temperature and final constant weight is recorded.

\section{7] In vitro drug release:}

To study the drug release from multilayered and bilayered patches (USP) XXX111-B rotating paddle method is used. Phosphate buffer ph 6.8 is used as a dissolution media. The in vitro buccal permeation through the buccal mucosa is performed using Fran z type glass diffusion cell.

\section{8] Permeation study of buccal patch:}

Phosphate buffer ph 6.8 is filled in receptor compartment and hydrodynamics is maintained by stirring with a magnetic bead. Samples are withdrawn at predetermined time intervals and analyzed.

\section{9] Measurement of mechanical properties:}

It includes tensile strength and elongation at break is evaluated using a tensile tester. Clamps are designed to secure the patch without crushing it during the test, the lower clamp held stationary and strips are pulled apart by the upper clamp. When the tip breaks the force and elongation of film is noted.

\section{0] Stability study in human saliva:}

The human saliva is collected from humans and stability study of bilayered and multilayered patches is performed 
in human saliva. Buccal patches are placed in separated petridish containing $5 \mathrm{ml}$ of human saliva and placed in an oven. At regular time interval, dose formulation with better bioavailability is needed ${ }^{19}$.

\section{ORALLY DIS INTEGRATING FILMS:}

Orally disintegrating films is new drug delivery system for the oral delivery of drugs. Because of convenience and ease of use over other dosage form, orally disintegrating films have been introduced in the market ${ }^{32}$. Orally disintegrating films disintegrate within few seconds when placed on the tongue without the need of water. It was developed on the basis of transdermal patch technology. Recently oral films containing breath fresheners, API and vitamin supplements 31 .

\section{FEATURES OF ORALLY DIS INTEGRATING FILMS ${ }^{32}$ :}

1] Available in various shape and size.

2] Excellent mucoadhesion.

3] Rapid release.

4] Unobstructive.

5] Thin elegant film.

6] Fast disintegration.

\section{ADVANTAGES OF ORALLY DIS INTEGRATING FILMS :}

1] They can be administered anytime without water.

2] They are portable and flexible in nature ${ }^{31}$.

3] They have accurate dosing in safe and effecious format.

4] Taste masking of drug should be done.

5] They provide rapid dissolution and disintegration in the oral cavity due to its large surface area ${ }^{33}$.

6] They are suitable for geriatric and pediatric patients.

7] It has potential to improve the onset of action and increase the safety of medicament.

8] It provides new business opportunities like patent extension, product promotion and product differentiation 34

\section{DISADVANTAGES OF ORALLY DISINTEGRATING FILMS ${ }^{38}$ :}

1] High dose is avoided in orally disintegrating films formulation.

2] Special packing is required since they are temperature and moisture sensitive.

3] There is a problem of dose uniformity in formulating ODF's.

FORMULATIONS CONS IDERATION IN ODF's ${ }^{32,33}$ :

1] Active pharmaceutical ingredient (API).

2] Film forming polymers.

3] Saliva simu lating agent.

4] Sweetening agent.

5] Colouring agent.

(c) 2011, JDDT. All Rights Reserved
6] Plasticizers.

7] Flavoring agents'

\section{METHODS OF PREPARATION OF ODF's :}

There are various methods for preparation of ODF's which are enlisted below-

1] Sol vent casting method ${ }^{39}$ :

In this method all water soluble excipients are dissolved in water and after then water soluble polymers and drug are added to form a homogeneous mixture at high shear processor. Finally solution is poured into the Petri plate for drying. In this method, solvent evaporates at high temperature.

\section{2] Semisolid casting method:}

In these method water soluble polymers and acid insoluble polymers are added which is prepared by the sodium hydroxide and ammonium hydroxide. At last, sufficient amount of plasticizer is also added to form a gel. Cellulose acetate phthalate and cellulose acetate butyrate are acid insoluble polymers which are used to prepare films. The film thickness is 0.015 to 0.05 inches ${ }^{40}$.

\section{3] Solid dispersion extrusion:}

In this method solid dispersion is prepared and immiscible components are extruded and finally mixed with the drug. Finally with the help of dies solid dispersion are shaped in to films ${ }^{34}$.

\section{4] Rolling method:}

In this method, a drug and polymer suspension is prepared containing water or alcohol as solvent and subjected to the roller ${ }^{41}$.The suspension is then add on drum for evaporating the solvent and cutted into desired size and shapes $^{33}$.

\section{5] Hot melt extrusion:}

In these method, drug is mixed with carrier in the solid form and and dried granular material is put into the extruder ${ }^{42}$.The screw speed should be $15 \mathrm{rpm}$.In the extruder solid for carrier and drug is melt and placed in to dies and cutted into desired size and shapes ${ }^{41}$.

\section{6] Freeze dried wafer:}

In this method, dehydration of water occurs ${ }^{41}$. It reduces pressure from surrounding and allows the water in material to sublime directly .It is also called as lyophilisation method.

\section{DIFFER ENT TECHNOLOGY US ED IN ODF's:}

Technology used in formu lating ODF's are enlisted below-

1] Solu leaves.

2] Wafertab.

3] Micap.

4] Foam burst.

5] Xgel. 


\section{EVALUATING PARAMET ERS OF ODF's :}

Various evaluating parameters of ODF's are-

\section{1] Thickness ${ }^{42}$ :}

It can be measured by micrometer screw guage or vernier calipers. For content uniformity and uniform film thickness, it can be checked at five different points by calibrated dig ital mic ro meter.

\section{2] Mechanical properties:}

a) Tensile strength- It is point at which film is break ${ }^{32}$

Tensile strength $=$ Load at failure $\times 100 \div$ Film thickness $\times$ Film width

b) Percent elongation: It is calculated by the following formulae

$\%$ elongation $=$ Increase in length $\times 100 /$ Orig inal length

\section{3] Fol ding endurance:}

Folding endurance value is determined by the number of times the film is folded without breaking.

\section{4] Tear resistance:}

Tear resistance value is the maximum force or stress required to tear the specimen $[43,45]$. It is expressed in Newton's or Pound-Force.

\section{5] Surface ph of film:}

It can be measured by placing the film on the surface of $1.5 \% \mathrm{w} / \mathrm{v}$ agar gel by placing ph paper on film.

\section{6] In vitro disintegration time:}

In this method, films are placed in the mouth of volunteer and check the time to disintegrate the film ${ }^{44}$.

\section{7] Contact angle:}

It is measured by goniometer.In these method distilled water drop placed on dry film and picture is taken within $10 \mathrm{sec}$ for angle determination ${ }^{32}$.

\section{8] In vitro dissolution test:}

It is performed in USPX 111 type 11 apparatus in $0.1 \mathrm{~N}$ HCL and 6.8 phosphate buffer. The samples withdrawn at various time intervals and analyzed spectrophotometrically 42

\section{9] Drug content and drug unifor mity:}

It is determined by estimating the API content in individual film ${ }^{46}$. It is also determined by specification in different pharmacopeia.

\section{0] Trans parency:}

It is determined using a simple UV spectrophotometer ${ }^{46}$.In these film samples are cut into rectangles and kept on internal side of spectrophotometer cell.

\section{1] Taste evaluation:}

It is going with panel of volunteers and the test sensors analyzed the sweetness level of taste masking agents.

\section{2] Packaging:}

The most commonly used packaging format is aluminum pouch. Rapid card is used for packaging of Rapid films which is patented and proprietary packaging system of APR-Labtech ${ }^{41,44}$.

Table 4: Commercially Thin Film Oral Dosage Form Products ${ }^{32,41}$ :

\begin{tabular}{cccc}
\hline S No. & Product & Manufacturer & Active Pharmaceuticalagent \\
\hline $\mathbf{1}$ & Triaminic & Novartis & Dextromethorphan $\mathrm{HBr}$ \\
$\mathbf{2}$ & Triaminic & Novartis & Diphenhy dramine $\mathrm{HCl}$ \\
$\mathbf{3}$ & Theraflu & Novartis & Dextromethorphan $\mathrm{HBr}$ \\
$\mathbf{4}$ & Gas-X & Novartis & Simethicone \\
$\mathbf{5}$ & Sudafed & Pfizer & Phenylephrine $\mathrm{HCl}$ \\
$\mathbf{6}$ & Benadryl & Pfizer & Diphenhydramine $\mathrm{HCl}$ \\
$\mathbf{7}$ & Chloraseptic & Prestige & Benzocaine Menthol \\
$\mathbf{8}$ & Suppress & InnoZen & Menthol \\
$\mathbf{9}$ & Orajel & Del & Menthol/Pectin \\
$\mathbf{1 0}$ & Listerine & Pfizer & Cool mint \\
\hline
\end{tabular}

\section{CHEWING GUMS AND CHEWAB LE TAB LETS ${ }^{31,}$ 55 :}

Chewable tablets can be taken without water and chewed before swallowing. They are suitable for children's $\geq 4$ years. They contains coated particles of active drugs. The chewable tablets have palatable taste and contain noncritical excipents.

For children's above 2 years chewable tablets contain cyclodextrin for taste masking and solubilization. It seems to be safe for oral use. Use of ion resins or cyclodextrins is used for taste masking of adults dosage form. It is not always acceptable for childrens.It increases bioavailability by immediate disintegration, patient acceptance and patient convinence.A common problem of chewable tablet is that the membranes coated the active particles can break. The drug unpleasant taste is often perceived by the patient due to the breakdown of me mbranes 54 .

Chewing gum tablet consist of two cohered chewing gum modules. It was formed by compression of chewing gum granules. The compressed chewing gum tablet composed of chewing gum ingredients with acceptable rheological properties. Addition of water or heat is not required for formulating chewing gums. A palatable, edible soft chewable medication vehicle was patented by Paulson et al.Chewing gums takes 10-20 minutes for complete release 
of drug. This are used for systemic or local treatment.Superpep ${ }^{\circledR}$ travel gu $\mathrm{m}$ is a product for children's $\geq 6$ years. It contains four sweeteners such as aspartame, sucrose, sorbitol and sodium saccharine to mask the taste for entire chewing time.

\section{ADVANTAGES OF CHEWING GUMS ${ }^{47,48}$ :}

1] It does not required water to swallow.

2] It is suitable for children's and patients having difficulty in swallowing.

3] It enhances bioavailability of drug and avoids first pass metabolism.

3] It simulates flow of saliva in mouth.

5] It causes fast onset of action due to rapidly release of active ingredients.

6] It neutralized plaque acids.
DISADVANTAGES OF CHEWING GUMS: 1] It contains sorbitol which causes diarrhea and flatulence

2] Cinnamon, flavoring agents like additives present in chewing gum may causes ulcers in oral cavity.

3] Prolonged chewing of chewing gum results in pain in facial muscles 49 .

\section{COMPOS ITION OF CHEW ING GUMS ${ }^{50}$ :}

1] Water insoluble gums -

These contain Elastomers, Resins, Fats and Oil and Inorganic fillers.

\section{2] Water soluble gums -}

These contain high intensity sweeteners, Bulk sweeteners, Flavouring agents, Softners, Emulsifiers, Colours and antioxidants.

Table 5: List of Some of the Commercialy Available Che wing Gums ${ }^{53}$ :

\begin{tabular}{|c|c|c|c|c|}
\hline S.N. & $\begin{array}{l}\text { TRADE } \\
\text { MARKTM }\end{array}$ & $\begin{array}{l}\text { ACTIVE } \\
\text { SUBSTANCES }\end{array}$ & AIM & $\begin{array}{l}\text { COMMERCIAL } \\
\text { AVAILIB ILITY }\end{array}$ \\
\hline 1 & Aspergum & Aspirin & Pain Relief & North America \\
\hline 2 & Nicorette & Nicotine & Smoking cessation & World wide \\
\hline 3 & Nicotinelle & Nicotine & Smoking cessation & Western Europe, Australia \\
\hline 4 & Travell & Dimenhy drinate & Travel illness & Italy, Switzerland \\
\hline 5 & Superpep & Dimenhy drinate & Travel illness & Germany, Switzerland \\
\hline 6 & Endekay Vit C & Vit $\mathrm{C}$ & General health & United Kingdom \\
\hline 7 & Stamil Vit C & Vit C & General health & Australia \\
\hline 8 & Brain & DHA and CCE & Enhanced brain activity & Japan \\
\hline 9 & Stay alert & Caffeine & Alertness & USA \\
\hline 10 & Café Coffee & Caffeine & Alertness & Japan \\
\hline 11 & Buzz Gum & Guarana & Alertness & United Kingdom \\
\hline 12 & Go Gum & Guarana & Alertness & Australia \\
\hline 13 & Chroma slim & CR & Diet & USA \\
\hline 14 & Chooz & Calciumcarbonate & Stomach acid, neutralization & USA \\
\hline
\end{tabular}

\section{DIFFERENT METHODS OF PREPARATION OF CHEWING GUMS:}

\section{1] Fusion/Traditional Method ${ }^{52}$ :}

In this method, components of gums, sweeteners, softeners, active ingredients and excipient are added in a kettle mixer. This is then passing through a series of rollers. In these processes, a light coating of finely powdered sugar is added to the gum. At last, gum is cutted into desired shape and size.

\section{2] Cooling, Grinding and Tabletting Method ${ }^{48}$ :}

This method is mainly used to lower the moisture content and reduces the problems mentioned in conventional method.

To achieve desired properties of chewing gum and to facilitate cooling, grinding certain additives are added to the chewing gum composition such as -
a) Use of grinding agent.
b) Use of Anticaking agent.

For Tabletting a Fluidized Bed Reactor can be used. In these method after the removal of coolant from the powder, it can be mixed with other ingredients such as binders, lubricants, sweeteners, colouring agent etc.in a suitable blender such as high shear mixture ${ }^{48}$.

\section{3] Use of Direct Compression Che wing Gum Excipients 51:}

This method can be used to overcome the limitations of melting and freezing method. In these methods, chewing gum can be manufactured under CGMP conditions and complies with Food Chemical Codex and FDA specifications. So they can be considered as (GRAS) "Generally Regarded as Safe" 47.

\section{APPLICATIONS OF CHEWING GUMS:}

1] It is used to inhibit plaque growth.

2] It is used to mask the bitter taste of chlorhe xidine ${ }^{49}$.

3] It is used to cure and prevent oral disease.

4] It is used to provide a prolonged local effect ${ }^{52}$. 
5] It contains active substances like guaran, chromium, caffeine to treat obesity.

6] It is used in treatment of headache, minor pains and muscular aches.

7] It is also beneficial for Allergy, Cold and Cough, Xerostomia, Acidity, An xiety, Motion sickness etc ${ }^{47}$.

\section{ORAL WAFERS ${ }^{55}$ :}

Oral wafers are also called or dispersible strips. These are thin films of $2-8 \mathrm{~cm}$ square area and $20-500 \mu \mathrm{m}$ thickness. It contains $\leq 50 \mathrm{mg}$ of API.Wafers are administered on the tongue and dissolves in the mouth without intake of water within a few seconds. Now a days, few OTC products are available for preschool childrens. The products contains many excipients such as film forming agents derived from starch and cellulose,flavours,colouring agents, sweeteners and traces of class 3 residual solvents. The residual solvents act processing aids.

Oral wafers are usually provided as unit dose in child proof pouches. Recently, the first prescription-only oral wafer is Setofilm ${ }^{\circledR}$ approved in Europe for use in children's from 6 months onward by Applied Pharma Research and Labtec and MonoSol Rx.

\section{SPECIAL FORMULATIONS- LOLLIPOPS AND GUMMY BEARS:}

Special oral formulations are lollipops and Gummy bears. Lollipops are for children's above 3 years and gummy REFERENCES:

1. Puttalingaiah L, Kavitha K, Mani T, Fast disintegrat ing tablets: An overview of formulation, technology and evaluation, RJPBCS, 2011, 2(2), 589 .

2. Fini A, Bergamante V, Gian CC, Ronchi C, Carlos AF. "Rapid Dispersible/Slow Releasing Ibuprofen Tablets" European Journal of Pharmaceutics and Biopharmaceutics, 2008, 6,335-341.

3. Gavaskar B, Kumar SV, Sharan G, Nagaraju M and Rao YM. Present investigations and future prospects of oral disintegrating tablets: A Review, IJPSR, 2010, 1(8), 45-47.

4.Wagh MA, Dilip KP, Salunkhe KS, Chavan NV, Daga VR.Techniques used in orally disintegrating drug delivery system. INJDD, 2010, 2, 98107.

5.Sagar A, Prafulla S. Chaudhari, Rajesh J, Sandip SK, Rishikesh V.,Trushal VC, Mouth Dissolving Tablets" An Innovative,IJPSR,2009,1(5),132.

6.Allen LV., Wang B, Particulate Support Matrix for making a rapidly dissolving tablet, 1997, US patent 5595761,97-98.

7. Hirani JJ, Rathord DA, Vadalia KR, Orally disintegrating tablets: A review, Trop J Pharm Res, 2009, 8(2), 161-172.

8. Mahaveer PR, Orally disintegrating tablets: A future prospectus, Int J Pharm Sci Bi, 1998, 3(1), 71-79.

9.Pahwa R, Piplani M, Sharma PC, Kaushik D, Nanda S, Orally disintegrat ing tablets-Friendly to pediatrics and geriatrics, Arch Appl Sci Res. ,2010, 2(2), 35-48.

10. Kunal PR, Orally disintegrating tablets: A future prospectus, Int J Pharm Sci Bio, 2010, 1(1) 71-79.

11. Krishnakanth B, Pankaj N, Margret CR, J Chemical and Pharmaceutical Res, 2009, 1, 163-177.

12. Patidar A, Mishra P, Main P, Harsoliya M.S. andAgrawal S, A review on- recent advancement in the development of rapid disintegrat ing tablet, int j pharm research, 2011, 1(1), 32-34.

13. Brown D, Orally disintegrating tablets: Taste over speed, Drug Delivry Tech 2001, 3(6), 58-61.

14. Lies MC, Athert on AD, Copping NM, US Patent 1993, 5,825.

15.Ghosh TK, Chatterjee DJ, Pfister WR, Scientific and Regulatory

Considerations from a Clinical Pharmacology and Biopharmaceutical Perspective, 2005,2(1),337-356

16. Nagar P, Kusum S, Iti C,Verma M, Mohd Y,Azad K, Sharma R and Gupta N, Orally disintegrating tablets: formulation, preparation techniques and evaluation, Journal of Applied Pharmaceutical Science,2011, 01 (04),35-45. bears are for children's above 3 years. These are sweet in taste. Due to its sweet taste they ate attractive to children's and parents can easily administered drug to their children's.

Lollipops are formulate depend upon the individual taste. It is trendy in US compounding pharmacies ${ }^{55}$. However it should be labeled that these "special" formulation are not "sweet" and kept out from reach of children's.

\section{CONCLUS ION:}

The area of formulating orally disintegrating dosage forms is aims at increasing the patient compliance and decreasing the disintegration time. It also aims of masking the objectionable taste of active ingredients. As compared to other complicated processes such as freeze drying etc., formulation of orally disintegrating dosage form is easy and overall cost of manufacturing is low. The potential of orally disintegrating dosage form to disintegrate in the oral cavity within seconds, fast onset of action, increasing patient compliance and taste masking of active ingredient makes it an attractive drug delivery form. However , an addition of active ingredient in dosage form like orally disintegrating tablets, orally disintegrating films, oral wafers, buccal patches and chewing gums are excepted to provide a highly acceptable means of delivering drug to geriatric and pediatric patients.So.in forth coming years oral drug delivery becomes a much popular drug delivery.

17. Kamal S, Pooja M, Verma S, Navneet S and Kumar A, Mouth dissolving tablets: An overview on future compaction in oral formulation technologies. Der Pharmacia Sinica, 2010, 1 (1), 179-187.

18. Tian, W., Lan gridge, J; us20060100214 2006, 1(3), 76.

19. Edsman K, et al, Pharmaceutical applications of mucoadhesion for the non-oral routes, Journal of pharmacy \& pharmacology, 2005, 57, 3-19.

20. Nouri, N., Zuccarelli, J., Bruna, E, Chauveau C: US20020098227, 2002, 98 .

21. Pramodkumar TM et al, Oral transmucosal drug delivery systems, Indian drug, 2004, 41(2), 63-12.

22. Aungst BJ and Rogers NJ, Site Dependence of Absorption- Promoting Actions of Laureth9, Na Salicylate, Na2EDTA, and Aprotinin on Rectal, Nasal, and Buccal Insulin Delivery Pharm. Res, 1988, 5 (5), 305-308.

23. Shangraw R, Mitrevej A, and Shah, Pharm Tech, 1980, 4(10), 48-57.

24. Steward A et al, The Effect of Enhancers on the Buccal Absorption of Hybrid (BDBB) Alpha-Int erferon, Int.J. Pharm, 1994, 104,145-149.

25. Kumar R, Patil MB, Sachin R, Patil K, Mahesh SR, Int J PharmTech Res,2009,1(2), 210-214.

26.Avani R, Gosai K, Sanjay B, Patil A, Krutika K, Sawant S, Int J Pharm Sci and Nano, 2008, 1(1), 1-6.

27. R. Fuisz, S. R. Cherukuri, US Patent 5,654,003, Aug 5,1997,43.

28. Shrishand S, Sarasija S, Plantago O, Mucilage in Design of Fast disintegrating Tablets, Indian journal of pharmaceutical sciences, 1997,72(1), 41-43.

29. Botzalakis JE, Dngsburger LL, Drug Development and Industrial Pharmacy, 1988, 14 (9), 1235-1248.

30. Giradkar KP, et al, Design development and in vitro evaluation of bioadhesive dosage form for buccal route, International journal of pharma research \& development, 2010, 2, 21-23.

31. Honey G, Rai P, Rana V, Tiwary KA, Orally Disintegration systems: Innovations in formulation and Technology, Recent Patents on Drug Delivery \&Formulation, 2008, 2,258-274.

32. Bhupinder B, Jangra S, Kaur M, Singh H., Orally Fast Dissolving films: Innovation in formulation and technology, International journal of pharmaceutical science review and research ,2010,9(2), 56.

33. Cilruzo F, Cupone EI, Diclofenac fast-dissolving film: suppression of bitterness by a taste-sensing system, Drug Dev. Ind. Pharmacy, 2010, 1(8), 74 .

34. Alpesh R. Patel H, dharmendra S, prajapati K, Jignyasha A, Fast dissolving films as a newer vent ure in fast dissolving dosage forms, Int. J. Drug Dev. \& Res, 2010, 2(2), 232-246. 
Reeta et al

Jo urnal of Drug Delivery \& Therapeutics; 2012, 2(3): 87-96

35. Amir H, et al, Systemic drug delivery via the buccal mucosal route, Pharmaceuticaltechnology, 2011, 1(4), 1-27.

36. Shidhaye SS, et al, Mucoadhesive bilayered patches for administration of sumatript an, AAPS pharm sci tech, 2009, 9(3), 89.

37. Makino T, Yamada M, Kikut a J, European Patent, 1993,76-77.

38. Dhere P, Pat wekar S.L, Review on preparation and evaluation of oral disintegrat ing films, 2011, 3(4), 56-57.

39.M Nishimura, K Matsuura, T Tsukioka, H Yamashita, NInagaki, T Sugiyama, Y Itoh, In vitro and in vivo characteristics of prochlorperazine oral disintegrating film, International Journal of Pharmaceutical Scienses, 2009,368 (2),98-102.

40. Shimoda H, Taniguchi K, Preparation of fast dissolving oral thin film containing dexamethasone: A possible application to antiemetic during cancer chemotherapy, European Journal of Pharmaceutics and Biopharmaceutics, 2009, 73,361-365.

41 Arya A, Amrish C, Sharma V and Kamala P. Fast dissolving Oral films: An innovative drug delivery system and dosage form, International journal of chem., 2010, 2(1), 576-583.

42. Shivani S, Satyam G, Garg G, Garg V, Sharma PK, Formulation and evaluation of rapidly disintegrating film of Levocitrizine hydrochloride, 2010, 2(2), 434-439.

43. Dixit RP, Puthli SP, Oral strip technology: Overview and future potential, Journal of Controlled Release, 2009, 139, 94-97.

44. Han JH, Floros J, Casting antimicrobial packaging films and measuring their physical properties and antimicrobial activity, Journal of Plastic Film and Sheeting, 1997, 13,287-297.
45.Basani G, Vijaya SK, Guru S,International Journal of pharmaceutical Science,2010,2(3),46-47.

46. Apoorva M, Chhabra NK, Aggarwal G, Formulation and characterization of fast dissolving buccal films: A review,2011,3(1), 152165 .

47. Morjaria Y, Irwin WJ, Barnett PX, Chan RS, Conway BR, In Vitro Release of Nicotine from Chewing Gum Formulations, Dissolution Technologies, 2004, 1(5), 12-15.

48.Conway B, Chewing Gum as a Drug Delivery System, The Drug Delivery Companies Report Autumn/Winter, 2003,1(4) 33-35.

49.Goldberg LD, Ditchek NT, Chewing gum diarrhea, Am J Dig Dis, 1978, 23(6), 568

50. Zyck DJ, Greenberg MJ, Barkalow DG, Marske SW, Schnell PG, Mazzone P, Method of making coated chewing gum products containing various ant acids, US Patent, 2003, 6, 535 .

51. Jacobsen J, Christrup L.L, Jensen NH, Medicated Chewing Gum. Pros and Cons, Am J Drug Deliv, 2004, 2 (2), 75-88.

52.Dodds M, Hiesh S, Johnson D,The effect of increased mastication by daily gum chewing on salivary gland output \& dental plaque acidogenicity, J Dent Res, 1991, 1(3), 1474-1478.

53.Ezhumalai K, Ilavarasan P, Rajalakshmi AN, Sathiyaraj U, Murali RM, Medicated chewing gum-A novel drug delivery technique for systemic and targeted drug delivery, 2011,3(1),725-744.

54. Paulsen NE, Johnson R, Coffe M, US20080075759, 2008, 55.

55. Stoltenberg I, Winzenberg G, Breit kreutz J, Solid oral dosage form for children's-formulation, excipients and acceptance issue, Journal of applied Theuraptic Research, 2010,7(4),13-14. 